\title{
THE
}

\section{College Women's Experiences of Intimate Partner Violence: Exploring Mental Health Issues}

\author{
F. Scott Christopher \\ Tiffani S. Kisler \\ University of Rhode Island, tkisler@uri.edu
}

Follow this and additional works at: https://digitalcommons.uri.edu/hdf_facpubs

Terms of Use

All rights reserved under copyright.

\section{Citation/Publisher Attribution}

F. Scott Christopher \& Tiffani S. Kisler (2012) College Women's Experiences of Intimate Partner Violence: Exploring Mental Health Issues, NASPA Journal About Women in Higher Education, 5:2, 166-183, DOI: 10.1515/njawhe-2012-1116

Available at:: http://dx.doi.org/10.1515/njawhe-2012-1116

This Article is brought to you for free and open access by the Human Development and Family Science at DigitalCommons@URI. It has been accepted for inclusion in Human Development and Family Science Faculty Publications by an authorized administrator of DigitalCommons@URI. For more information, please contact digitalcommons-group@uri.edu. 


\title{
College Women's Experiences of Intimate Partner Violence: Exploring Mental Health Issues
}

\author{
F. Scott Christopher \\ Professor \& Director \\ Undergraduate Studies School of Social \& Family Dynamics \\ Arizona State University
}

Tiffani S. Kisler

Assistant Professor

Human Development \& Family Studies

University of Rhode Island

College women's experiences with sexual and physical violence are so common that campus interventions are needed. To help guide these, we surveyed 339 college women and asked: (a) are college women's experiences with different types of relational violence interrelated and (b) are there patterns of association between types of violence and mental health symptoms? Analyses showed that experiences with verbal aggression, and minor and major physical violence overlapped. Experiences of sexual assault and minor physical violence also co-occurred. Moreover, women who encountered verbal and physical, but not sexual violence, suffered from symptoms of hostility, anxiety, and depression; those who encountered sexual coercion displayed signs of depression. We explore the implications of these findings for those who work with college women.

Contemporary research has consistently revealed that physical and sexual aggression in intimate relationships is a serious problem on college campuses (e.g., Crown \& Roberts, 2007; Smith, White, \& Holland, 2003).

Correspondence concerning this article should be addressed to F. Scott Christopher, Professor \& Director Undergraduate Studies School of Social \& Family Dynamics, Arizona State University, scott.christopher@asu.edu or Tiffani S. Kisler, Assistant Professor Human Development \& Family Studies, University of Rhode Island, tkisler@uri.edu 
In Carr's (2005) assessment of the scope of college victimization, she noted that physical assault accounts for $69 \%$ of violent campus crimes and that $20-25 \%$ of college women will experience either attempted or completed rape. Carr additionally observed that violent crime is likely underreported. Critically, college women are aware of the potential of experiencing intimate partner violence, and their awareness contributes to personal views that their campus is not safe for women (Kelly \& Torres, 2006).

Not surprisingly, experiencing intimate partner violence is often associated with decreased mental health. Amar and Gennaro (2005), for example, reported that college women experiencing physical violence potentially suffer from mental health problems. Golding (1999) specifically showed that women's experiences with interpersonal violence are consistently associated with elevated risk of depression. Previous investigations into violence and mental health, however, typically have focused on sexual or physical victimization, or have aggregated the two (e.g., Amar \& Gennaro, 2005). In addition, investigators have not always included a broad array of mental health indicators. Thus, the question of whether there are distinct patterns in the association between the different types of violence and specific mental health symptoms has been left unanswered.

In light of these shortcomings, our study had two primary purposes. First, we explored the degree of overlap between different types of Intimate Partner Violence (IPV) college women experience. Second, we tested to see if unique relationships existed between experiencing the different forms of IPV and specific mental health outcomes. The importance of our study rests on an established dynamic: college women infrequently reveal their victimization to others (Carr, 2005; Ogletree, 1993). If they do disclose, it is often to a confidant rather than to a college professional.

The importance of our research is underscored in the dynamic of limited or nondisclosure. Young women who live with current or past IPV and poor mental health (Kelly \& Torres, 2006) may come to the attention of college personnel because of mental health distress. Nonetheless, such women may be reluctant to disclose that an intimate partner has victimized them and may define their experiences as acceptable if they still remain in the relationship (Lloyd \& Emery, 1999). Thus, if our investigation revealed specific ties between types of IPV and mental health problems, the findings could alert college professionals of the need to inquire about possible experiences with IPV when young women initially show signs of mental health distress. Understanding (a) how different types of IPV overlap, as well as (b) how they are uniquely related to mental health 
problems, can aid those who work with female students as they take steps to address both of these areas of concern.

\section{Intimate Partner Violence}

Saltzman (2004) called for the use of the term "intimate partner violence" to capture the types of violence that occur within romantic relationships. Yet, the types of violence vary in terms of physicality, focus, and potential for physical injury. For instance, Straus, Hamby, Boney-McCoy, and Sugarman (1996) conceptualized verbal aggression as including behaviors such as insulting, swearing, sulking, or saying something to spite a partner. Further, they posited that verbal aggression is a means of asserting control. Alternatively, sexual coercion involves several influence techniques, such as being physically persistent, using psychological manipulation, and trying to get a partner intoxicated with the goal of gaining sexual access (see Christopher \& Kisler, 2004 for a review). Neither verbal abuse nor sexual coercion involves the potential for physical injury by themselves.

Other types of IPV involve either threats or use of increased physicality and risk of physical injury. Straus et al. (1996), for instance, differentiated between minor and major physical violence. Behaviors that typify minor physical violence include throwing objects as well as pushing, grabbing, or shoving, whereas kicking, hitting, choking, or beating characterize major physical violence. Scholars also have made distinctions in sexual aggression. Christopher (2001), citing factor analytic studies (Christopher \& Frandsen, 1990; Meyer, Vivian, \& O'Leary, 1998), stipulated that sexual assault involves the threat or use of force to attain sexual access and, therefore, is distinct from sexual coercion.

Qualitative work has suggested that college women's experiences with the specific forms of violence may overlap (e.g., Lloyd \& Emery, 1999). Yet few investigators have included measures representing a full range of intimate violence. Subsequently, researchers have not examined how the various types of violence are interrelated. Thus, our first research question was: How are college women's experiences with the verbal aggression, minor physical violence, major physical violence, sexual coercion, and sexual assault related?

\section{Intimate Partner Violence and Mental Health}

Young women who experience IPV are at increased risk for a number of mental health problems. Amar and Gennaro (2005), for instance, 
compared female college students who had and who had not experienced IPV. Those who experienced violence scored higher on indicators of depression, anxiety, somatization (chronic/persistent physical symptoms with no identifiable origin), interpersonal sensitivity (low self-worth and/or feeling marginalized), and hostility. Other investigators reported similar findings (McGruder-Johnson, Davidson, Gleaves, Stock, \& Finch, 2000; Messman-Moore, Long, \& Siegfried, 2000).

Although previous investigators clearly have shown that college women's experiences with aggression put them at risk for decreased mental health functioning, they failed to examine whether there is a unique relationship between the type of aggression and specific mental health problem areas. Exploring this issue is particularly important given that young women may come to the attention of college professionals because of mental health problems but may also be reluctant to reveal that they have been the victim of IPV. Knowledge about how the different types of violence are uniquely related to specific mental health problems can help those who work with college students to better tailor their support and interventions for these problems. Hence, our second research question was: Are there specific patterns of association between different types of aggression and specific mental health symptoms?

\section{Method}

\section{Participants}

The sample consisted of 339 college women from a large metropolitan southwestern university and with a mean age of 21.6 years $(S D=3.6)$. Most respondents were Euro-American (76\%), fewer were Hispanic (12\%), African American (5\%), Asian/Pacific Islander (3\%), Native American (1\%) or another minority (3\%). Most participants had completed high school (56\%), or a 2-year degree from a community college (25\%); fewer held a bachelor's degree $(13 \%)$, a graduate degree $(3 \%)$, or marked another educational achievement (3\%).

\section{Procedure}

Male and female undergraduates enrolled in general studies courses taught by the first author were invited to participate in an on-line survey for extra credit. The first survey item asked respondents to report their gender. 
Male respondents then "clicked" through to a web page with directions on how to receive their extra credit. Female respondents continued on to the survey (the few men who inadvertently completed the survey were culled from the sample). The survey instructions directed women to focus on their most recent relationship in which they "engaged in sexual interaction with (your relationship partner) when you did not want to because of the way your partner mistreated you." These instructions were followed by measures that queried about experiences with verbal, physical, and sexual violence with the same partner as well as experiences with mental health problems. The women were then given instructions on how to receive their extra credit. These procedures were approved by the university Internal Review Board.

\section{Measures}

Sexual aggression. The women indicated on a scale of 0 (never) to 6 (more than 20 times) whether their partners had utilized any tactics from a list of 13 aggressive behaviors in order to engage in sexual behaviors with them. We selected these items from existing scales for which factor analysis in the original studies revealed differences in whether the items measured sexual coercion or sexual assault (e.g., Christopher \& Frandsen, 1990; Meyer et al., 1998). Similar to this previous work, factor analysis of the 13 items revealed that 9 items could be used to form two scales (all scales in the study were scored by averaging the items). Four items measured sexual coercion $(\alpha=.76)$ : Your partner applied "psychological pressure," "lied to you," "ridiculed you," and "got you drunk, high, or both." Five items measured sexual assault ( $\alpha=.87)$ : Your partner "held you while you resisted," "would not let you leave," "would not let you get up," "threatened to use force," and "used force."

Verbal and physical violence. We used the Conflict Tactics Scale (Straus, 1979) to measure verbal aggression, minor physical violence, and major physical violence. Women reported the frequency of specific behaviors on a scale of 0 (never) to 6 (more than 20 times) for 18 different behaviors. Verbal aggression $(\alpha=.91)$ included items such as participants' partners insulted or swore, stomped out of the room or house (or yard), sulked and refused to talk, and did or said something to spite the respondent. Minor physical violence $(\alpha=.88)$ included items such as the partner threw something at the participant and slapped pushed, grabbed, or shoved them. Major physical violence $(\alpha=.68)$ included items such as kicking or 
biting the participant, beating up or hitting them with a fist or object, and threatening with or actually using a knife or gun.

Mental health symptoms. We used five subscales from the Hopkins Brief Symptom Checklist-90 (Derogatis \& Melisaratos, 1983) to measure mental health symptoms. The women indicated on a scale of 0 (not at all) to 4 (extremely) whether a specific problem had distressed or bothered them during the previous 7 days. Specific subscales included Interpersonal Sensitivity ( $\alpha=.77$; e.g., feeling very self-conscious with others, feeling that people are unfriendly or dislike you), Somatization $(\alpha=.83$; e.g., hot or cold spells, faintness or dizziness, nausea or upset stomach), Hostility $(\alpha=.77$; e.g., getting into frequent arguments, feeling easily annoyed or irritated, having urges to beat, injure, or harm someone), Depression ( $\alpha=$ .87; e.g., feeling hopeless about the future, feelings of worthlessness, feeling no interest in things, $)$, and Anxiety ( $\alpha=.87$; e.g., nervousness or shakiness inside, feeling fearful, spells of terror or panic).

\section{Results}

\section{Women's Relationships}

We asked the women about the type of relationship they had with their violent partners. Of the 339 respondents, half reported they had an exclusive dating relationship (50\%) and a third (36\%) indicated they had a casual dating relationship. Fewer women were cohabiting without being engaged (9\%), cohabiting while engaged (1\%), engaged but not cohabiting $(2 \%)$, or were married (2.1\%). Most women had ended their relationship at the time of the survey $(83.5 \%)$, but some were still with the referent partner $(16.5 \%)$.

\section{Interrelationship of Sexual and Physical Aggression}

The first research question focused on the interrelationships between college women's experiences with verbal aggression, minor physical violence, major physical violence, sexual coercion, and sexual assault. We addressed this question in two ways. First, we calculated correlations between the different types of IPV (see Table 1). Our description of these findings focused on the effect size of the correlations, as they provide the best marker for the degree of overlap (i.e., an $r$ value of .10 represents a small effect size, .30 a moderate effect size, .50 a large effect size; Cohen, 
TABLE 1. Correlations

\begin{tabular}{lcccc}
\hline & Sexual assault & Sexual coercion & Verbal aggression & Minor violence \\
\hline Sexual assault & - & & & \\
Sexual coercion & $.52^{* *}$ & - & & \\
Verbal aggression & $.25^{* *}$ & $.30^{* *}$ & - & \\
Minor violence & $.33^{* *}$ & $.25^{* *}$ & $.72^{* *}$ & - \\
Major violence & $.28^{* *}$ & $.18^{* *}$ & $.52^{* *}$ & $.82^{* *}$ \\
\hline
\end{tabular}

** Correlation is significant at the 0.01 level.

1992). There was a large effect size for the correlation between sexual coercion and sexual assault, suggesting that women's experiences with the two types of sexual aggression overlapped. Correlations with large effect sizes also emerged for verbal aggression, minor physical violence, and major physical violence; women's experiences with these three types of aggression also co-occurred. A medium effect size correlation emerged between minor violence and sexual assault, suggesting somewhat less overlap for these two types of violence. Although the remaining correlations were significant, their effect sizes were small. Thus, there was less interconnectedness in the case of sexual coercion with verbal aggression, minor physical violence, and major physical violence, as well as in the case of sexual assault with verbal aggression and major violence on a bivariate level.

To further explore the degree of overlap in college women's experiences between the five types of interpersonal violence, we performed a cluster analysis on the variables using a single linkage method (different clustering methods resulted in similar results). When clustering individuals often the goal is to create typologies, however our goal was to examine the pattern of clustering between measures in order to gain insight into how college women's experiences with different types of aggression are interrelated. Borgen and Barnett (1987) recommended this procedure when the goal is to examine how variables form patterns within groups. The advantage of cluster analysis over correlation analyses is that the interrelationships of all of the types of violence are considered simultaneously in the cluster analyses, whereas with correlations only bivariate associations were analyzed. The cluster analyses, therefore, provide additional insight into how these variables are interrelated on a multivariate level.

The clustering analysis began with each type of violence as its own cluster and then joined related types of violence to one another to form a new cluster (see Table 2). This proceeded until all of the variables were joined into a single cluster. At step one, major and minor physical violence 
TABLE 2. Cluster Analysis

\begin{tabular}{lcccccccc}
\hline $\begin{array}{l}\text { Number } \\
\text { of clusters }\end{array}$ & Minor violence & & Major violence & & $\begin{array}{c}\text { Verbal } \\
\text { aggression }\end{array}$ & Sexual assault & $\begin{array}{c}\text { Psychological } \\
\text { coercion }\end{array}$ \\
\hline 1 & $X$ & $X$ & $X$ & $X$ & $X$ & $X$ & $X$ & $X$ \\
2 & $X$ & $X$ & $X$ & $X$ & $X$ & $X$ & $X$ & $X$ \\
3 & $X$ & $X$ & $X$ & $X$ & $X$ & & $X$ & $X$ \\
4 & $X$ & $X$ & $X$ & & $X$ & & $X$ & $X$ \\
5 & $X$ & & $X$ & & $X$ & & $X$ & $X$ \\
\hline
\end{tabular}

formed a cluster. In the second step, verbal aggression joined with major and minor violence. Sexual assault joined this cluster in the third step, and then sexual coercion joined the other variables in the final step.

\section{Victimization Experiences and Mental Health Symptoms}

Our second research question asked whether there were patterns of association between different types of aggression and symptoms of specific mental health problems. We used canonical correlation analysis to address this question, as it can identify patterns of relationships between two sets of variables. Canonical correlation analysis has similarities to multiple regression except there are multiple independent variables (types of IPV) and multiple dependent variables (types of mental health problems) used to derive canonical correlates. Therefore, tests initially focus on how many significant canonical correlates emerge from the analyses (UCLA Academic Technology Services, 2006). There are also parallels between canonical correlation analyses and factor analysis in that canonical correlation coefficients indicate the strength of the association between individual variables and a canonical correlate. Thus, the next step in the analysis is to examine the strength of the standardized canonical coefficients for each significant canonical correlate in order to provide insight into how a unique set of independent variables was related to a unique set of dependent variables.

Two significant canonical correlates emerged from the analyses. The first significant correlate (Wilks' Lambda $=.76 ; F=3.69, p=.0001$ ) explained $70.38 \%$ of the variance in the two sets of variables and had a canonical correlate of .41. An examination of the standardized canonical coefficients (see Table 3) showed that young college women's experiences of verbal aggression (standardized canonical coefficient $=-.95$ ), minor forms of physical violence $(-.85)$, and major forms of physical violence $(-.72)$ were most strongly related to symptoms indicating possible problems of 
TABLE 3. Standardized Canonical Coefficients

\begin{tabular}{lclc}
\hline & First correlate & & Second correlate \\
\hline $\begin{array}{l}\text { Types of aggression } \\
\text { Verbal aggression }\end{array}$ & -.95 & Sexual coercion & .71 \\
Minor violence & -.85 & Minor violence & -.36 \\
Major violence & -.72 & Major violence & -.24 \\
Sexual coercion & -.36 & Sexual assault & .20 \\
Sexual assault & -.45 & Verbal aggression & .08 \\
Mental health indicators & & & \\
Hostility & -.98 & Depression & .64 \\
Anxiety & -.72 & Interpersonal sensitivity & .53 \\
Depression & -.68 & Anxiety & .26 \\
Interpersonal sensitivity & -.50 & Hostility & -.12 \\
Somatization & -.39 & Somatization & .05 \\
\hline
\end{tabular}

hostility (-.98), anxiety (-.72), and depression (-.68), and to a lesser extent problems of heightened interpersonal sensitivity (-.50).

The second significant correlate (Wilks' Lambda $=.82 ; F=1.76$, $p=.03$ ) explained an additional $17.42 \%$ of the variance in the two sets of variables above and beyond the first significant covariate and had a canonical correlate of .22. The standardized canonical coefficients for this correlate revealed that women's experiences with sexual coercion (.71) were most strongly related to signs of depression (.64) and, again to a lesser extent, to heightened interpersonal sensitivity $(.53)$.

\section{Additional Analyses: Breakup Status}

The sample included women who varied in whether they were still in a relationship with their violent partner. To provide additional insight into the dynamics of abusive relationships, we compared these two groups on the variables of the study. Although no differences emerged for the measures of mental health symptoms, differences existed for all of the violence measures with the exception of verbal aggression. Those women who were still with their partners reported higher levels of minor physical violence (together $M=.87$; broken up $M=.52 ; F=4.21, p=.04 ; d=.30)$ and major physical violence (together $M=.27$; broken up $M=.15 ; F=2.81, p=$ $.09 ; d=.25$ ), but lower levels of sexual coercion (together $M=1.08$; broken up $M=2.34 ; F=26.26, p=.001 ; d=.75)$ and sexual assault (together $M=.81$; broken up $M=1.20 ; F=4.38, p=.04 ; d=.31$ ). Of note, all of these effect sizes were small with the exception of sexual 
coercion, which had a large effect size. Experiences with sexual coercion, therefore, were more strongly related to breakup status than were other experiences of violence.

\section{Discussion}

\section{Overlapping Experiences}

Both the correlation and the cluster analyses point to college women's overlapping experiences with verbal aggression, minor physical violence, and major physical violence. There are two noncompeting possible explanations for the overlap. According to M. P. Johnson (2006), the most common type of partner-related violence is situational couple violence. In situational couple violence, physical violence often emerges from partners' verbal aggression; partners physically lash out at one another during a heated argument. M. P. Johnson speculated that this form of violence is argument-specific and typically not associated with either partner's consistent attempts to dominate the relationship. Moreover, situational couple violence infrequently involves severe violence. Although we did not procure reports of violence from relational partners, the empirical links between verbal aggression and minor violence in our findings suggest that some of the women were involved in situational couple violence. Moreover, the findings that women still in a relationship reported slightly higher levels of minor physical violence suggests that some women may tolerate low levels of physical violence. M. P. Johnson speculated that this would be the case if the women also engaged in these same behaviors.

Nevertheless, the linkage between the women's experiences with minor and major physical violence suggests that the sample may also have included a small proportion of women whose experiences were more physical, involving more intense levels of violence. Three (1\%) women in our study had partners use a knife or a gun, 9 (2.6\%) indicated their partner had beat them, $46(13.6 \%)$ had partners attempt to or successfully hit them with objects, and $40(11.8 \%)$ had a partner hit them with a fist, kick them, or bite them. These more severe forms of violence would be characteristic of intimate terrorism according to M. P. Johnson (2006). The motivation of an intimate terrorist is to control and emotionally abuse one's partner. The control is often achieved by relying on severe and injurious violence, which may be used when lesser levels of physical violence and/or verbal aggression are unsuccessful at achieving control. Such overlapping experiences would 
contribute to the correlation in our results. In addition, the finding that young women who still were in relationships reported higher levels of major violence may reflect the fact that women in very violent relationships can feel trapped with few alternatives (M. P. Johnson, 2006).

The analyses that focused on sexual aggression provided additional insight into how women's experiences with violence overlap. The correlation analyses suggest that victimization experiences with sexual coercion and sexual assault were linked, yet sexual coercion joined the clustering only at the final step, after sexual assault had joined at the second to the last step. Collectively, these findings suggest two possible pathways for sexual aggression. In one, male partners' use of sexual aggression is motivated by the need to make a sexual conquest (see Christopher, 2001 for a review). Sexual coercive techniques are used initially, as they involve less overt attempts to gain sexual access. If these fail, male assailants may then progress to the more forceful and overt control attempts captured by our measure of sexual assault. They restrain the women who resist their sexual advances (53\% of the women experienced this), do not let them leave (experienced by 60\%), physically hold them down (experienced by $22 \%$ ), and at times threaten force (experienced by 21.5\%). Interestingly, the direction of the mean difference for sexual coercion associated with breakup status and the large effect size suggest that college women do not always tolerate sexual coercion; it appears to play a notable role in women's decision to end a relationship. It may be that sexual coercion occurs earlier in relationship development than other forms of IPV. Women may be less invested in the relationship at these stages and thereby find it easier to break it off with a partner.

Still, the analyses did show a pattern of association between sexual assault and minor and major forms of physical violence. These experiences may have involved instances of intimate partner terrorism. Recall that men who engage in this form of violence are motivated to control and humiliate their partners (M. P. Johnson, 2006). It seems logical to conclude that they accomplish this through the use of sexually assaultive influence techniques that dominate and humiliate their romantic partners. Collectively, our results, when paired with earlier research and theorizing, suggest that college women experience IPV via multiple pathways.

\section{Intimate Partner Violence and Mental Health}

The canonical correlation analysis showed a pattern of association between verbal aggression, minor violence, and major violence, on the one 
hand, and indications that women in the sample showed signs of problems with hostility, anxiety, depression, and to a lesser extent, interpersonal sensitivity, on the other hand. The strong connections between hostility, verbal aggression, and the two forms of physical violence are not surprising. Young women's expression of hostility, especially if directed at a partner, may trigger situational couple violence. Moreover, experiencing verbal aggression and physical violence would also likely result in feelings of hostility. Although previous investigations have consistently shown connections between men's hostility and their use of physical violence toward their partner (Schumacher, Feldbau-Kohn, Slep, \& Heyman, 2000), very few investigators have looked for an association between women's experiences with physical violence and their personal feelings of hostility. In one exception, White and Widom (2003) found such a link, but their measure of violence was limited to women hitting, grabbing, or shoving their partner at least once during the previous year. Thus, their study focused on women's limited expression of violence. Our results broaden the understanding by showing that college women's experiences with being victimized by verbal aggression, minor physical violence, and major physical violence are strongly linked to elevated expressions of hostility.

Although hostility is recognized as an external manifestation of mental distress, the remaining associations point to internal manifestations. Depression has been linked to both physical and sexual victimization of women in previous studies (Amar \& Gennaro, 2005; Golding, 1999). Our study extends this body of knowledge by showing that indications of depression are associated with experiences of sexual coercion after controlling for the contributions of verbal aggression and physical violence.

Anxiety symptoms were linked to experiences with verbal aggression and physical violence, but not to experiences of sexual aggression. Differences in the couple dynamics associated with the two clusters of violence may explain this differential association. For example, Basile (1999) investigated ways in which women acquiesced to unwanted sex in established relationships. Some women engaged in unwanted sex because their partners' protestations wore them down; it was easier to have sex than put up with their partners' continual pressure. If such a dynamic characterized the young women in the present study, it suggests that the threat for this type of violence was somewhat contained and may have occurred only occur in private. Other studies support this line of thinking by showing that sexual aggression occurs primarily in private settings such as a residence or a bedroom (Gwartney-Gibbs \& Stockard, 1989; Miller \& Marshall, 1987). Any 
resulting anxiety in the women, therefore, may not fully permeate other aspects of their lives. In contrast, women whose lives are punctuated by verbal aggression and physical violence may experience these at unpredictable moments without warning (Lloyd \& Emery, 1999). Living in constant fear of violence may result in higher levels of anxiety. Future research can help to shed light on the dynamics behind this finding.

Finally, interpersonal sensitivity was moderately associated with all forms of violence. This suggests that college women who experience IPV are prone to feelings of inferiority and emotional vulnerability and may believe that others dislike them. Other scholars have shown that victimized women often question their self-worth (Zweig, Crockett, Sayer, \& Vicary, 1999) and feel guilty (Lloyd \& Emery, 1999). Our results suggest that the co-occurrence of interpersonal sensitivity symptoms with other mental health symptoms is common when women experience IPV. Thus, the pairings of expression of interpersonal worthlessness with the other mental health problems in our findings provide clues to college professionals who work with female students that these women's problems may be more extensive than they initially appear.

\section{Limitations}

As is true of all research, our study has limitations. The nonrandom sample limited the ability to generalize the findings. Online surveys potentially involve multiple submissions, technical difficulties, and issues with respondents' lack of experience with online surveys. Although we took steps to guard against such issues by eliminating incomplete responses, comparing responses with the same IP address, checking for outliers, and making the survey available for an expanded period of time, such problems may have influenced our results in unforeseen ways.

Another potential limitation is that the inclusion criteria focused primarily on sexual aggression. Thus, there was a risk that experiences with sexual violence were overrepresented when compared to experiences with verbal and physical violence. We would offer that this may not have been the case given the range and frequency of experiences with physical violence reported by the women in the sample.

\section{Implications}

College professionals who work with female students have often called for interventions to prevent relational violence. Cantalupo (2010) used a 
legal argument to encourage colleges to respond to female students' sexual victimization by male peers. Edwards and Headrick (2008) offered approaches for engaging college men in sexual violence prevention. Amar and Gennaro (2005) called for colleges to respond to female-directed physical violence. Our findings that verbal, physical, and sexual violence are interrelated in unique ways suggest that college policies and interventions that focus solely on one type of violence may not be efficacious because such efforts fail to acknowledge the complexity of violence in college women's romantic relationships. We suggest that violence prevention and intervention programs be designed to educate students on the intersections of verbal, physical, and sexual violence and corresponding mental health issues. Moreover, these educational efforts should be offered to both students and campus personnel who work closely with students. Such efforts may be particularly critical given that college women rarely reveal that they have experienced IPV, and if they do so it is more likely to be to a friend than to a professional.

In addition, our findings demonstrate that college women who experience IPV are at elevated risk for experiencing mental health distress in unique ways dependent on the type of relational violence. Given that college women infrequently disclose their victimization, signs of mental health distress may be how these women come to the attention of college professionals. Those who work in residence halls or academic advising or who provide other individualized services to students are apt to notice female students who become hostile, show signs of depression or anxiousness, and/or express feelings of low self-worth. These professionals can be educated to see these as potentially critical times to intervene.

For instance, although overt hostility in female students warrants an appropriate response, our findings suggest that a resident hall associate faced with a hostile woman may want to find a private, calmer moment at a later time to inquire about the type of relational conflict she is experiencing. Similarly, faculty who notice that a female student is not fully participating in a class or academic advisors with women who repetitively miss appointments can be educated to see these incidents as possible signs of depression and/or low self-worth. It may be critical that these professionals make an extra effort to reach out to such students and ask about their emotional state and whether there are problems in their romantic relationships. Correspondingly, it is imperative that universities have interventions in place to respond to this need and strive to ensure that college personnel are aware 
of such resources so that they can appropriately refer these young women when their "talks" reveal a need for specialized treatment.

Finally, our findings can help counselors who staff campus mental health clinics. Many college women seek counseling because they suffer from the same mental health problems investigated in the present study (R. W. Johnson et al., 1989). Our research shows the importance of querying these women about possible relational violence during intake interviews or during the course of treatment. Victimized women who seek counseling may not understand how their experiences with violence are linked to their mental health difficulties. Armed with the findings from the present study, therapists can guide women toward such insights during therapy.

\section{References}

Amar, A. F., \& Gennaro, S. (2005). Dating violence in college women: Associated physical injury, healthcare usage, and mental health symptoms. Nursing Research, 53, 235-242. doi:10.1097/00006199-20050700000005

Basile, K. C. (2002). Prevalence of wife rape and other intimate partner sexual coercion in a nationally representative sample of women. Violence and Victims, 17, 511-524. doi:10.1891/vivi.17.5.511.33717

Borgen, F. H., \& Barnett, D. C. (1987). Applying clustering analysis to counseling psychology, Journal of Counseling Psychology, 34, 45-468. doi:10.1037//0022-0167.34.4.456

Cantalupo, N. C. (2010). How should colleges and universities respond to peer sexual violence on campus? What the current legal environment tells us. Journal About Women in Higher Education, 3, 49-84. doi:10.2202/1940-7890.1044

Carr, J. L. (2005). American college health white paper. Baltimore, MD: American College Health Association.

Christopher, F. S. (2001). To dance the dance: A symbolic interactional exploration of premarital sexuality. Mahwah, NJ: Lawrence Erlbaum.

Christopher, F. S., \& Frandsen, M. M. (1990). Strategies of influence in sex and dating. Journal of Social and Personal Relationships, 7, 89-107. doi:10.1177/0265407590071005

Christopher, F. S., \& Kisler, T. S. (2004). Sexual aggression in romantic relationships. In J. Harvey, A. Wenzel, \& S. Sprecher (Eds.), The 
handbook of sexuality in close relationships (pp. 287-309). Hillsdale, NJ: Lawrence Erlbaum.

Cohen, J. (1992). A power primer. Psychological Bulletin, 112, 155-159. doi:10.1037//0033-2909.112.1.155

Crown, L., \& Roberts, L. J. (2007). Against their will: Young women's nonagentic sexual experiences. Journal of Social and Personal Relationships, 24, 385-405. doi:10.1177/0265407507077228

Derogatis, L. R., \& Melisaratos, N. (1983). The Brief Symptom Inventory: An introductory report. Psychological Medicine, 13, 595-605. doi: $10.1017 /$ S0033291700048017

Edwards, K. E., \& Headrick, T. (2008). She fears you: Teaching college men to end rape, Journal About Women in Higher Education, 1, 164-180. doi:10.2202/1940-7890.1009

Gwartney-Gibbs, P., \& Stockard, J. (1989). Courtship aggression and mixed sex peer groups. In M. A. Parage-Good \& J. E. Stets (Eds.), Violence in dating relationships: Emerging social issues (pp.185-204). New York, NY: Praeger.

Golding, J. M. (1999). Intimate partner violence as a risk factor for mental disorders: A meta-analysis. Journal of Family Violence, 14, 99-132. doi:10.1023/A:1022079418229

Johnson, M. P. (2006). Violence and abuse in personal relationships: Conflict, terror, and resistance in intimate partnerships. In A. L. Vagelisiti \& D. Perlman (Eds.), The Cambridge handbook of personal relationships (pp. 557-576). New York, NY: Cambridge University Press.

Johnson, R. W., Ellison, R. A., \& Heikkinen, C. A. (1989). Psychological symptoms of counseling center clients. Journal of Counseling Psychology, 36, 110-114. doi:10.1037//0022-0167.36.1.110

Kelly, B. T., \& Torres, A. (2006). Campus safety: Perceptions and experiences of women students. Journal of College Student Development, 47, 20-36. doi:10.1353/csd.2006.0007

Koss, M. P., Gidycz, C. A., \& Wisneiwski, N. (1987). The scope of rape: Incidence and prevalence of sexual aggression and victimization in a national sample of higher education students. Journal of Consulting and Clinical Psychology, 55, 162-170. doi:10.1037//0022-006X.55.2.162

Koss, M. P., Leonard, K. E., Beezley, D. A., \& Oros, C. J. (1985). Nonstranger sexual aggression: A discriminant analysis of the psychological characteristics of undetected offenders. Sex Roles, 12, 981-992. doi:10.1007/BF00288099 
Lloyd, S. A., \& Emery, B. C. (1999). Thedark side of dating: Physical and sexual violence. Thousand Oaks, CA: Sage.

Miller, B., \& Marshall, J. C. (1987). Coercive sex on the university campus. Journal of College Student Personnel, 47, 38-47.

McGruder-Johnson, A. K., Davidson, E. S., Gleaves, D. H., Stock, W., \& Finch, J. H. (2000). Interpersonal violence and posttraumatic symptomatology: The effects of ethnicity, gender, and exposure to violent events. Journal of Interpersonal Violence, 15, 205-221. doi:10.1177/088626000015002006

Messman-Moore, T. L., Long, P. J., \& Siegfried, N. J. (2000). The revictimization of child sexual abuse survivors: An examination of the adjustment of college women with child sexual abuse, adult sexual assault, and adult physical abuse. Child Maltreatment, 5, 18-27. doi:10.1177/1077559500005001003

Meyer, S. L., Vivian, D., \& O’Leary, D. K. (1998). Men's sexual aggression in marriage: Couples report. Violence Against Women, 4, 415-435. doi:10.1177/1077801298004004003

Ogletree, R. J. (1993). Sexual coercion experience and helpseeking behavior of college women. College Health, 41, 149-153. doi:10.1080/07448481.1993.9936316

Saltzman, L. (2004). Issues related to defining and measuring violence against women: Response to Kilpatrick. Journal of Interpersonal Violence, 19, 1235-1243. doi:10.1177/0886260504269680

Schumacher, J. A., Feldbau-Kohn, S., Slep, A. M. S., \& Heyman, R. E. (2001). Risk factors for male-to-female partner physical abuse. Aggression and Violent Behavior, 6, 281-352. doi:10.1016/S13591789(00)00027-6

Smith, P. H., White, J. H., \& Holland, L. J. (2003). A longitudinal perspective on dating violence among adolescent and collegeage women. American Journal of Public Health, 93, 1104-1109. doi:10.2105/AJPH.93.7.1104

Straus, M. A. (1979). Measuring intrafamily conflict and violence: The Conflict Tactics scales. Journal of Marriage and the Family, 41, 75-88. doi: $10.2307 / 351733$

Straus, M. A., Hamby, S. L., Boney-McCoy, S., \& Sugarman, D. B. (1996). The revised Conflict Tactics scales (CTS2): Development and preliminary psychometric data. Journal of Family Issues, 17, 283-316. doi:10.1177/019251396017003001 
UCLA Academic Technology Services. (2006). SPSS data analysis examples: Canonical correlation analysis. Retrieved from UCLA Academic Technology Services Stat Computing Website: http://www.ats.ucla.edu/ stat/spss/dae/canonical.htm

White, H. R., \& Widom, C. S. (2003). Intimate partner violence among abused and neglected children in young adulthood: The mediating effects of early aggression, antisocial personality, hostility, and alcohol problems. Aggressive Behavior, 29, 332-345. doi:10.1002/ab.10074

Zweig, J. M., Crockett, L. J., Sayer, A., \& Vicary, J. R. (1999). A longitudinal examination of the consequences of sexual victimization for rural young adult women. Journal of Sex Research, 36, 396-409. doi:10.1080/00224499909552012 